\title{
Organising the political coordination of knowledge and innovation policies
}

\author{
Dietmar Braun
}

\begin{abstract}
This special issue of Science and Public Policy takes up the recently discussed problem of political coordination in the 'third phase of innovation'. The introduction prepares the analytical ground for the four case studies that follow. It develops the image of a 'knowledge space' consisting of the four 'core' areas of innovation policy - higher education, professional education, basic research and technological research - and uses insights from administrative science and a number of science and policy studies that discuss the need for coordination in policy-making in knowledge and innovation systems. Different types of coordination are distinguished as well as various institutional levels within the political system that play a role in the overall capacity of improving political coordination. A number of problems and expectations are raised which are the starting point of reflections in the ensuing case studies.
\end{abstract}

I NNOVATION POLICY HAS ENTERED its third phase (OECD 2005a,b,c). While the first phase was characterised by a 'linear' view of innovation as an automatic spill-over process between basic knowledge and technological application, in the second phase non-linear and recursive interactions between a variety of actors participating in the quest for innovation were highlighted. With the 'national systems of innovation' approach, a systemic view of the innovation process became increasingly accepted (Lundvall, 1992; Edquist, 1997b). Innovation policies during this phase remained, however, sector-based and focused on the content of policies (OECD, 2005a). It is only in the third phase that innovation has come to be seen as the interplay of market and non-market forces and as denoting a policy of 'structuration', of frameworksetting that helps to correct 'market failures' and improve interactions between the different components of the 'innovation system'. These claims were clearly expressed for the first time by the Organisation for Economic Development and Cooperation (OECD) in 1999. The 'new role for government',

Professor Dietmar Braun is Directeur at the Institut d'Etudes Politiques et Internationales, Université de Lausanne, Anthropole, CH-1015 Lausanne, Switzerland. the OECD writes, is to 'secure framework conditions, remove barriers to innovation, enhancing technology diffusion, promoting networking and clustering and leveraging research and development' (OECD, 1999: 10).

Such 'systems management' needs

comprehensive and coherent policies that are characterised by a good match between individual instruments and objectives as well as by compatible instruments and objectives in different policy areas. (OECD, 1999: 71)

The problem is, however, that OECD countries seldom seem able to develop an 'encompassing, systemic-oriented innovation policy' that can 'accommodate the dynamism' occurring on the level of research and technology development.

An investigation into the political conditions needed to realise such an encompassing innovation policy has been neglected until now in the literature on innovation and is the thrust of this special issue of Science and Public Policy. The focus of the 'national systems of innovation' approach (Lundvall, 1992; Edquist, 1997b) has been on the firm; the 'triple helix' approach (Leydesdorff, 2000) analyses primarily universities. This does not mean that these two approaches would not recognise the importance of politics and policies. Quite the contrary: the 'national 
Dietmar Braun has been Professor of Political Science at the Institut d'Etudes Politiques et Internationales of the University of Lausanne since 1996 . He has also been research councillor at the Swiss National Science Foundation since 2004, and was editor of the Swiss Political Science Review between 2001 and 2004. He is an active member of the European Network of Excellence PRIME. He has worked on topics linked to science and technology issues since the beginning of the 1990s, especially on research funding policies and funding agencies. He was editor of a special issue of Science and Public Policy on principal-agent theory and research policy in 2003.

system of innovations' approach, in accordance with 'evolutionary economics', has overcome the typical neo-classical economic view of (political) institutions as retarding and disturbing factors in (market) innovation.

The 'triple helix' approach acknowledges interdependence between industry, universities, and the political sphere and has discovered a process of 'coevolution' in which government can and should encourage developments in innovation by defining the 'rules of the game', financial assistance, and the creation of new actors (Etzkowitz and Leydesdorff, 2000).

Despite this awareness of the importance of political decisions and policies, these approaches do not explain under which circumstances and by what causal mechanisms 'signals' from knowledge and innovation will be taken up and translated into political reforms.

Implicitly, both the national systems of innovation approach and the triple helix approach assume that there will be adaptation and congruence of political and innovation activities in the end, but they fail to explain how this happens.

Our main concern in this special issue is to overcome lack of knowledge regarding the political process of responding to changing dynamics in the 'environment', i.e. in knowledge and innovation sectors (the 'knowledge space'; see below). Systemicoriented knowledge and innovation policies need adequate structures and processes within the political system, most notably the capacity to coordinate different political activities of governing of knowledge and innovation.

We want to know about possible hurdles within the political system to setting up a more encompassing knowledge and innovation policy and under what circumstances and by what means we can expect they may be encountered. All case studies in this special issue take these questions as their starting point.

In the remainder of this introduction we intend to construct a heuristic model on the basis of a number of insightful studies that will help to guide the interpretation of the different cases in the special issue. We start with a presentation of the dynamics of the 'knowledge space' that, as the second step, induces reaction at the level of the political system by strengthening political coordination.

\section{Congruence of structures in the knowledge space}

The OECD Monit-project (OECD, 2005a), which dealt explicitly with the relationship between innovation dynamics on the one hand and the quest for political coordination on the other, as well as the 'systems of innovation' approach, generally start from the assumption that 'third level innovation policy' (OECD, 2005a) needs linking to a large variety of sectors and people in the innovation system. The 'centre' of the innovation system, which we will label the knowledge space, is formed by those sectors that are directly involved in the production, diffusion, and application of knowledge.

In order to develop a more analytical model we state that two dimensions structure the knowledge space: The first dimension defines the 'rationale', the meaning of the sector (Mayntz, 1988), which in our case is the production of knowledge, i.e. research, on the one hand, and the transmission and diffusion of knowledge, i.e. education, on the other. The second dimension concerns the 'motive of action': utilitarian-oriented or non-utilitarian-oriented. While non-utilitarian knowledge production is inspired by curiosity and the search for truth, the utilitarian motive leads to a quest for chances to apply fundamental knowledge and develop new technologies. Likewise, there is a difference between the higher education teacher transmitting scientific knowledge for general education and personality development purposes on one hand and, on the other, the vocational trainer and teacher who attempts to improve the chances of students on the labour market.

Figure 1 demonstrates that we can in this way distinguish between four knowledge-related sectors ${ }^{1}$ (higher education, vocational training and professional education, basic research, and technological research and development) that have their own orientation, traditions, cultures, (professional) roles, and institutionalisation.

The differentiation into sectors can cause difficulties for the exchange of 'resources' between sectors: vertically, the basic research sector needs the influx of young people for its research activities, while knowledge transmission in higher education depends on the creation of new knowledge by research. The interface between the higher education sector and the research sector is institutionalised in the form of universities and is also represented in the person of the university scientist who has two social roles: teacher and researcher. The vertical exchange relationship on the right side of the knowledge space is very similar: technological development profits from the influx of students educated in institutions of professional education, and vocational training needs input not only from enterprises in the economic sector but also from researchers who bring in new technological knowledge. Polytechnics are most often the kind of institutions that handle this transfer. 


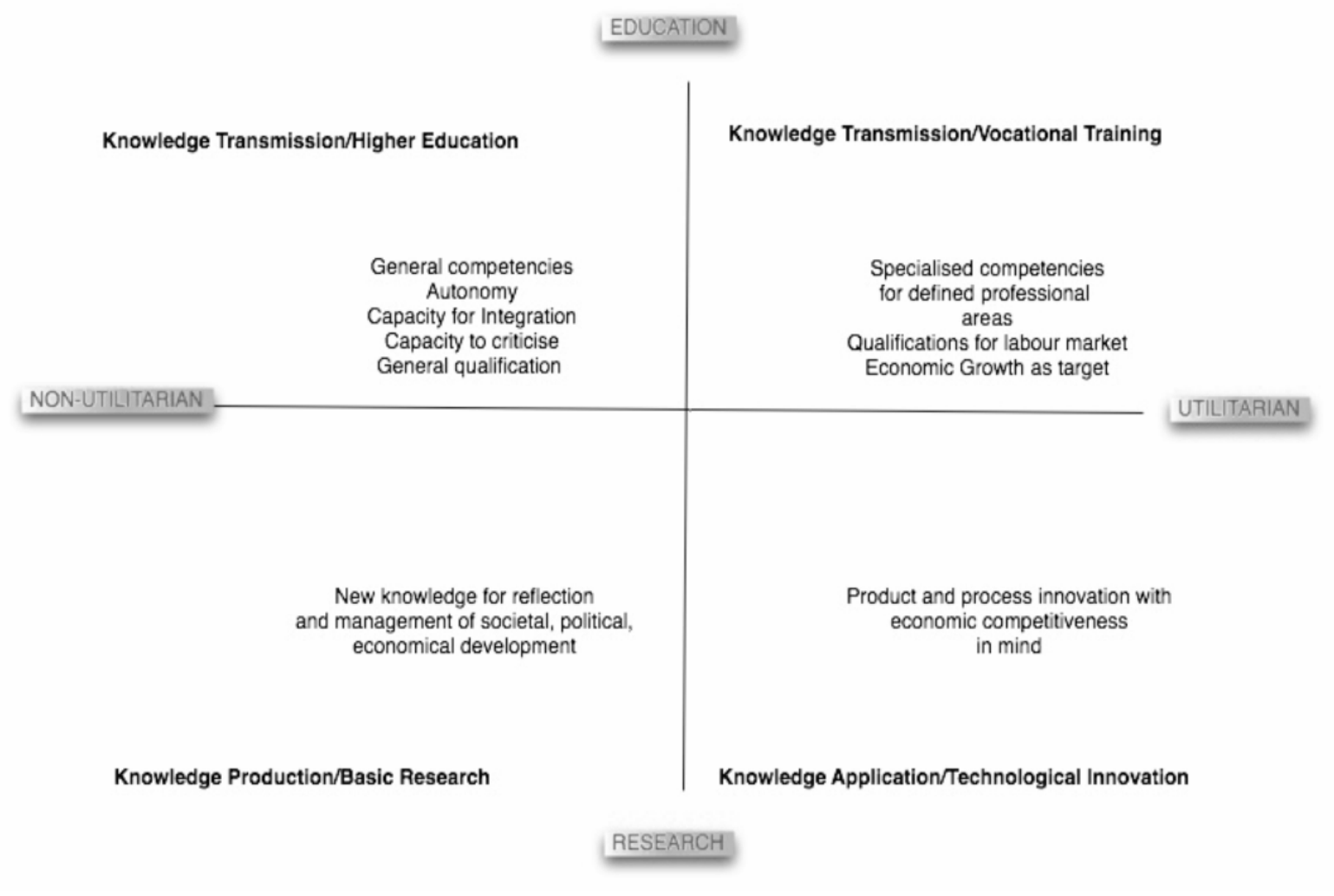

Figure 1. The four sectors of the knowledge space

While vertical transfer is rather unproblematic because it has been institutionalised in most countries for quite some time, this is not the case with horizontal exchange in the knowledge space. The transfer of higher education knowledge into the world of vocational training and vice versa has been tedious, and the transfer between fundamental research and technological development, as well as between technological knowledge and fundamental research (Stokes, 1997), has for a long time not been a priority given the linear science-push conception of innovation (Guston and Keniston, 1994). The main problem is that globalisation, generic technologies, and new conceptions of innovation exercise a continuing pressure on the institutionalisation of cooperation between the research sector and technological development.

The new conceptions developed in the framework of the knowledge society demand an opening of universities to the world of professions and enterprises while professional education institutions are pushed more and more to develop a more sophisticated and creative knowledge that creates a stronger interest in linking to the higher education sector. In other words, the dynamics in the knowledge space linked to innovation and the development of the knowledge society demand a strengthening of ties between higher education and professional education and between research and technological development. New institutions are in demand along with the emergence of new professional roles.

These are the points raised in the 'third phase of innovation policy': innovation today needs close interaction between these sectors, and the political system has the task of promoting the creation of interfaces and networks between the different sectors. But this can be done only if policy-makers adapt their goals and structures in such a way that the horizontal linkages in the knowledge space, above all, can be improved. If, however, the policy design is still inspired by the 'old linear models of innovation' and if the 'machinery of government' is still based on the differentiation into four different policy fields, ${ }^{2}$ a reform of 'goals' and 'structures' at the level of governance in order to adapt are needed. In other words, if 'networking' and 'interaction' become the main structuring principles in the knowledge space, new 'coordination' efforts are needed at the governance level.

\section{What kind of political coordination is needed?}

Coordination is a very illustrious notion that needs specification. What do we mean, exactly, when we speak of the need for coordination with regard to political governance in general and the machinery of government in particular? What kind of coordination do we need to be effective in innovation policy? How much political coordination is needed?

Though policy coordination is a recurring topic in administrative literature, we will search in vain for 'a systematic and useful approach to managing the coordination process' (Metcalfe, 1994) or for an unambiguous concept of coordination (Jordan and Schout, 2006). This is probably not so astonishing if we consider, as Boston does, that 'coordinating 


\section{What do we mean, exactly, when we speak of the need for coordination with regard to political governance in general and the machinery of government in particular?}

policies and administration is hard work, there is no easy recipe for success, nor a ready-made technology for coordination' (Boston, 1992: 100-101).

There are, nevertheless, useful heuristics that can help to find answers to the above questions. Painter (1981), for example, presents an instrumental definition by enumerating five objectives for policy coordination:

1. Avoidance, or at least minimization, of duplication and overlap.

2. Avoidance of policy inconsistencies.

3. Minimisation of conflict, both bureaucratic and political.

4. Quest for coherence and cohesion and an agreed ordering of priorities.

5. Promotion of a comprehensive or 'whole government' perspective against the constant advocacy of narrow, particularistic or sectoral perspectives.

Taking a closer look reveals two classes of objectives that usually play a role in the political system when coordination is discussed. The first three objectives are related to the more general objective of an 'efficient' state by reducing the costs of bureaucratic action; the last two objectives refer to the coherence of decision-making, which is the main point of the OECD Monit-project, i.e. drawing separated forces together in order to pursue common priorities and strategies developed on a 'systemic' level (the 'whole-government' perspective).

Another way to approach coordination is to ask what needs to be done. Painter (1981) and later Peters (2005) have already proposed a dual heuristic: 'policy' or 'functional' coordination is concerned with the development of a 'clear, consistent and agreed set of policies, the determination of priorities and the formulation of strategies for putting these policies into practice' (Boston, 1992: 89). In other words, it means coordination at the level of policy formulation. 'Administrative coordination' on the other hand, 'concerns the problem of getting everyone to pull in the same direction given agreement on what direction to go in' (Painter, 1981: 274). This is the level of policy implementation, and it is at this level that 'efficiency' problems, as mentioned above, can occur. Policy coordination as such does not absolutely need a whole-government perspective, but it implies at a minimum a perspective that is agreed upon by a number of political actors. It is clear that an encompassing innovation policy, as the OECD demands, needs both policy and administrative coordination.

This highlights that two steps need to be taken in order to arrive at political coordination. First, a common strategy must be developed, which means that one enters the 'political arena' where parties have to bargain for policies. Second, the cooperation of actors in the 'machinery of government' is needed in order to put common strategies into action. This does not preclude policy formulation at the ministerial level instead of at the cabinet level, though it will be difficult to develop a 'whole-government' perspective at this level. The cabinet level will usually have a fundamental role in policy coordination.

In order to achieve administrative coordination one could make another well-known analytical distinction of negative coordination (Scharpf, 1973, 2000), which means that actors - for example, two ministries - are not completely independent in their decision-making but obliged to take into account a negative backlash against their own actions by the other actor. Negative coordination avoids negative spill-over by information and often by formalised procedures in which other actors can react to the policy intentions of a ministry (e.g. the procedure of 'co-signing' of law proposals; interdepartmental committees, etc.). Negative coordination is a noncooperative game that leads, as Scharpf (2000) emphasises, to the mutual adjustment of actors, but not to concerted action nor to cohesiveness of policies. Negative coordination cannot suffice for the intentions of the 'third phase of innovation policy'.

'Positive coordination' goes, according to Peters (2006), one step further, as it implies more than mutual adjustment. Instead, actors start to cooperate with each other in order to deliver certain services. Such positive coordination can take place in interdepartmental committees, with the help of coordination divisions of ministries, within jointly managed policy programmes, or by participating in the writing of a White Paper on a common subject. It typically develops at the ministerial or agency level. In order to succeed, a 'win-win' game is needed in which each partner in the cooperation can ameliorate his or her position by participation in the cooperation. Such cooperation does not need a wholegovernment perspective. It can be restricted to certain domains. In fact, it can be quite limited and last only for a certain period. This again does not yet fulfil the need for an encompassing innovation policy, but positive coordination is certainly necessary at the level of administrative coordination when overall agreed-upon strategies must be implemented. It is a necessary condition for effectiveness, but it is not yet a sufficient condition.

Peters discusses still two other analytical levels of coordination that match the demands implicit in 'policy coordination': 'policy integration' strives for 
the coordination of goals; 'strategic coordination' aims at the development of encompassing common visions and strategies for the future. This is at the same time the most far-reaching type of coordination. Policy integration and strategic coordination are adequate means for achieving an encompassing innovation policy.

These different degrees of coordination can be ordered along the lines of a Guttman scale ${ }^{3}$ (see Figure 2).

In sum, in order to achieve an encompassing innovation policy, an overall agreement on objectives and strategic goals must be achieved. 'Policy coordination' is a sine qua non for this project. This does not mean that we can do without administrative coordination, which needs to be established at the level of implementation. There are two modes of coordination here, negative and positive coordination. Negative coordination would not suffice for achieving an encompassing policy, as it often exists today. Positive coordination seems to be the right degree of coordination at the implementation level, i.e. cooperation in the delivery of services on the base of commonly agreed-upon policy goals.

But the main question is, How can 'policy coordination' be achieved in the political system? By what means? How - and this is our main concern must the 'machinery of government' be organised to allow for 'policy coordination'?

According to existing studies, a number of hurdles must be overcome if political coordination is to reach the level of 'policy coordination': the institutional complexity of governance in knowledge sectors; cultural segmentation and standard interests at the level of ministries, agencies, and cabinet; and lack of strategic intelligence. We will attempt to highlight these points. We will first illustrate the complexity of institutional levels that play a role in the political system before discussing several institutional solutions in the light of the mentioned hurdles that play a role in this context.

\section{Institutional complexity}

On the basis of their comparative study on research and innovation governance in eight countries, Arnold and Boekholt (2003: 28) have distinguished four institutional levels that are relevant to innovation policies. Their fourth level corresponds to the level of the 'knowledge space', which in our heuristic model is on the same level as the political system. The three 'political' levels are the following: ${ }^{4}$

1. The level of the government and the cabinet, i.e. the level of 'high politics', where major objectives as well as institutional reforms of the machinery of government are decided.

2. The sectoral level of ministries, which is again subdivided into divisions and subdivisions; at this level, day-to-day decisions, decisions about implementation, and implementation activities take place.

3. The agency level, which, especially in research and technology policy, executes implementation tasks and often has - depending on its 'constitution' - a certain degree of operational autonomy, i.e. freedom to decide on how to implement policies.

Federal countries need to cope with an additional challenge, i.e. how to define competences and authority in the four sectors of the knowledge space between the federal and the regional level and how to cooperate. Education, for example, is more often than not the traditional prerogative of member states in federal countries, while the federal government often has the money to finance higher education

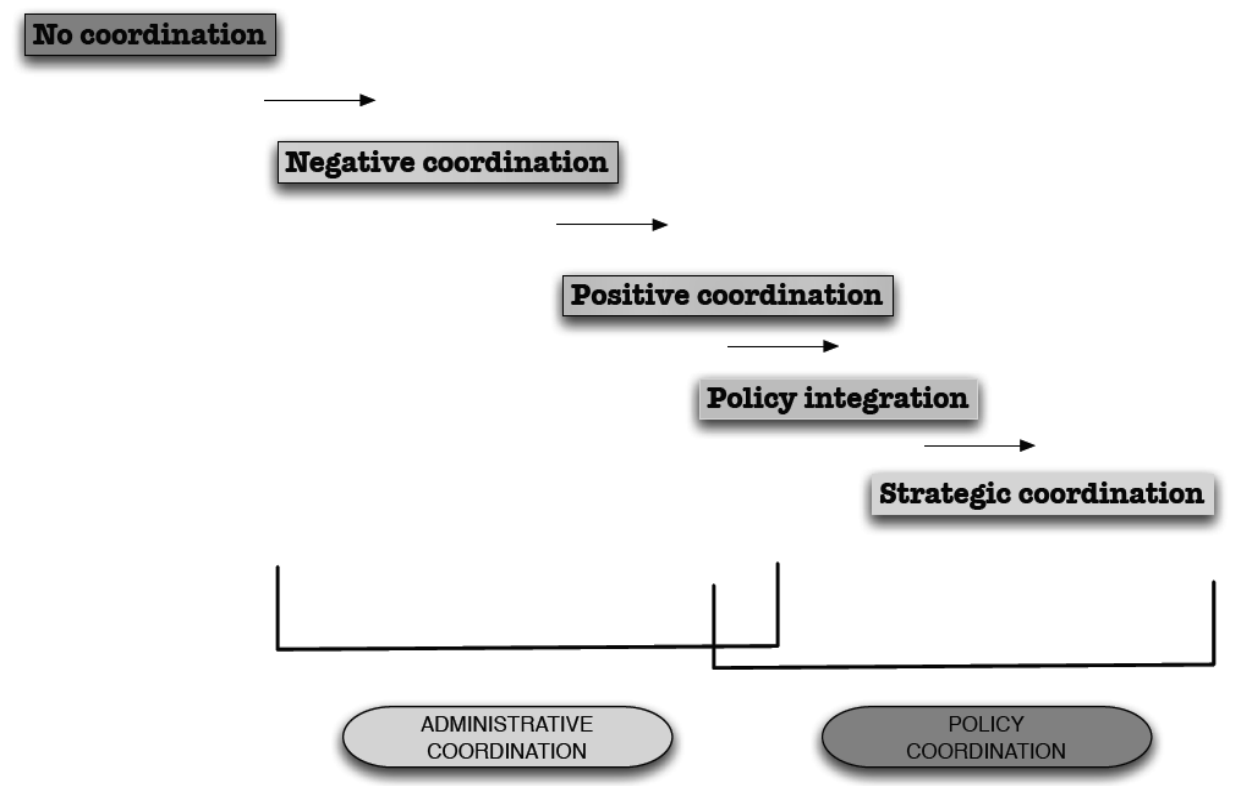

Figure 2. A Guttman scale of political coordination 


\section{From this it follows that one cannot expect that a decision at the level of the cabinet hierarchically flows from the ministerial down to the agency level}

institutions above all. This leads to demands for coordination. Concerning the machinery of government, the separation of powers may lead to lack of institutionalisation of certain policy sectors at the federal level if the member states dispose of the competences, or at least to a weak institutionalisation. We will see that this has been the case in both Germany and Switzerland.

A federal structure therefore has two effects: it structures the machinery of the 'federal' government and it influences decision-making structures about reorganisation. Federal governments have some leeway to decide on their internal organisation, but they must take into account the sensibilities of member states. In this way, federalism is an important additional horizontal level that is situated at the level of the cabinet, where major decisions about the policies and structures of the federal state are taking place $^{5}$ (Figure 3).

In addition to this differentiation into vertical institutional levels - the 'hardware' of governance is the 'software', i.e. the governance modi that bind the different institutional levels of the machinery of government together. In the Weberian understanding of bureaucracy, one would expect that 'hierarchy' is the glue that binds all institutional levels together. This concept is seriously contested. Decisions at the cabinet level will rarely be the decision of the Prime Minister, though there are political systems that function in this way. More often, cabinets decide collectively or leave major decision-making powers to the individual ministers. At the ministerial or sectoral level, the authority of the ministry depends on a number of factors, such as, for example, the size and homogeneity of the ministry, the certainty or uncertainty of outcomes to be expected from ministerial activities, the level of information, etc. Intermediary agencies, finally, are often quite detached from the direct influence of ministries. This is often expressed in the legal status of such agencies as 'semi-public' or private.

From this it follows that one cannot expect that a decision at the level of the cabinet hierarchically flows from the ministerial down to the agency level. Bargaining is a much more frequent mode of interaction than hierarchy and will be found at all three institutional levels. We may find that bargaining takes place 'under the shadow of hierarchy' (Benz, 2006), where the negotiating partners at the ministerial level are obliged to arrive at an understanding because the cabinet expects them do so. But it may also comprise the simple bargaining between organisations that have in principle the same 'authority status'.

The same holds for agencies that are dealing with each other. Another governance modus has been introduced into new public management in particular, i.e. coordination by contract, especially between ministries and agencies. Contracts are often the result of bargaining but introduce a more binding character of negotiation results.

There is no need to discuss such governance modes in detail here. The important message is that the complex arrangements at the level of the political system become even more complicated because of different co-existing governance modes that often

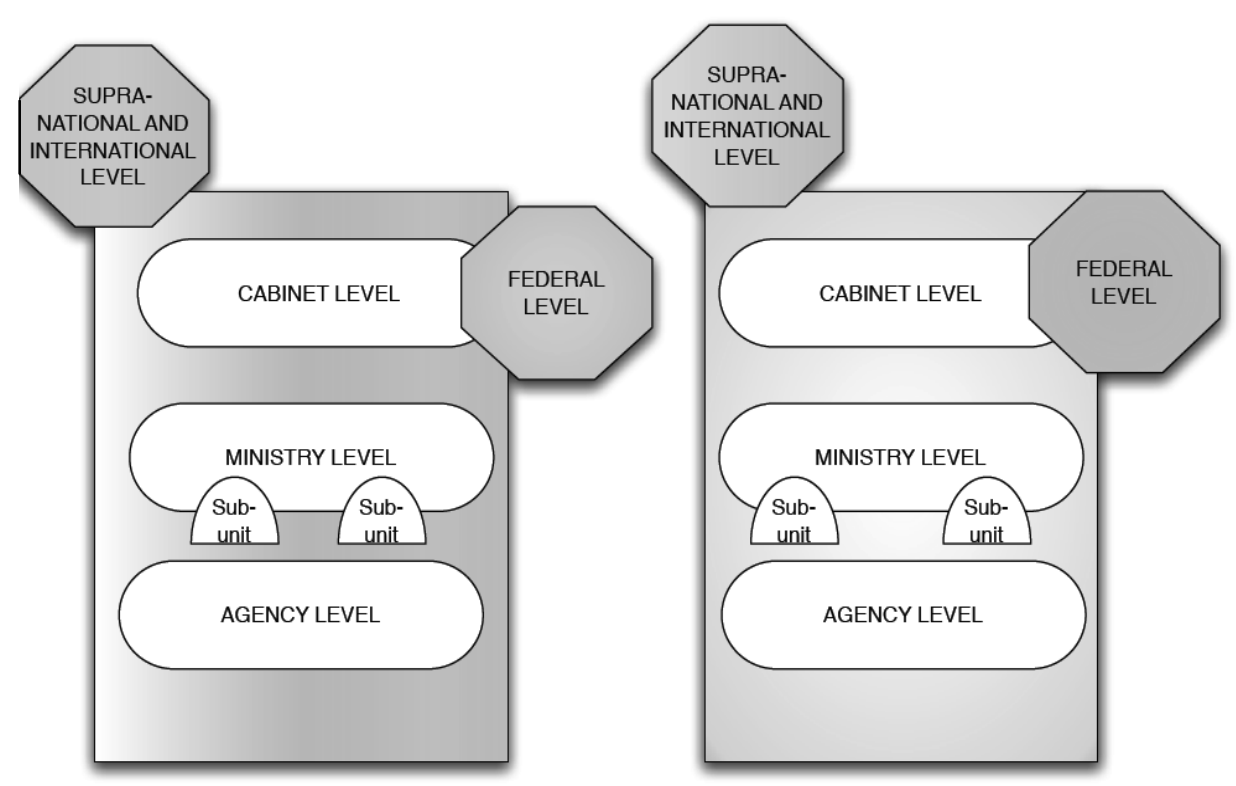

Figure 3. The institutional matrix of political governance 
do not allow for quick and hierarchical decisions. Reforms of the machinery of government are the result of a complex interplay of various institutional levels that is based mostly on bargaining between actors. This does not allow for a straightforward policy of institutional reform and restricts the room for manoeuvring of the political will and skill of policy-makers.

The 'matrix structure' of governance demonstrates, moreover, one other important point: the various institutional levels are interconnected. A reform of ministries may have implications for the representation of policy sectors on the level of the cabinet, and it will have effects on the governance and organisations of agencies. In a similar way, one may expect changes in the machinery of government if the composition of the government changes, and some reorganisation on the ministerial level will be needed if there is restructuring at the agency level. If one speaks, as the OECD does, of the development of a 'whole-government-perspective' that is needed, this means not only horizontal coordination but also vertical coordination of the different institutional levels. Reforming the machinery of government is a matter of multi-level governance applied to the level of the state.

\section{Five institutional options for promoting policy coordination}

The institutional matrix reveals the complexity of finding institutional solutions to coordination. In what follows we will discuss possible institutional options for coordination enhancement (interdepartmental bargaining; superministries; agency coordination) and what is needed on the level of the cabinet to engage in a strategy of policy coordination.

\section{External coordination}

On the ministerial level we can distinguish between two solutions for overcoming the 'utilitarian divide', i.e. 'external coordination' between ministries and 'internal coordination' within one superministry. In order to achieve external coordination, one option would be to rely on 'interdepartmental bargaining'. For example, one could group the often-used 'cosignature' procedure, ${ }^{6}$ budget procedures that require some coordination, or the set-up of 'interdepartmental committees' under this header. The administrative literature is extremely sceptical about reorganisation capacities by voluntary action of ministries. Two approaches explain this scepticism:

Sociological institutionalism (March and Olsen, 1984, 1989; Meyer and Scott, 1983) perceives ministries as organisations with a long history and tradition. On the basis of such history and tradition, organisations usually develop their own organisational culture and worldviews. Any coordination between organisations must be built on this foundation of different organisational routines, worldviews, and interests, which makes it difficult to build something new that would in principle overcome existing routines and develop a different causal view of the world, as an encompassing policy should. It will not be easy to convince the ministry of education and the ministry of economy and technology to unite forces if their previous policies have been based on a 'linear model of innovation' that functioned as the very rationale for the separation of these functions into two ministries. Any reform from outside obliging these ministries to launch such a new kind of cooperation, sociological institutionalism states, will fail. Only reforms that emerge incrementally from within the organisation have a chance of overcoming existing routines. This scepticism is shared by the studies of the OECD (2005b,c) and Technopolis (Arnold and Boekholt, 2003): Voluntary bargaining between ministries will be confined by existing routines and worldviews and any exogenous reform might fail because of implicit resistance of actors within ministries.

Purposive actor models (Peters, 1992), in particular rational choice theory, underline 'standard interests' that all corporate actors, including ministries, must defend. By standard interests is meant the resources needed for action, the domain of interest to be defended and expanded, and the degree of control over the domain of influence the actor needs as well as his or her autonomy in dealing with the domain of influence. Applying such a view leads us to the understanding that - as long as coordination cannot be imposed by hierarchy - positive coordination and 'policy coordination' can occur only if the standard interests of ministries are not in danger or if they can even be improved. Win-win games and 'Pareto-optimal' pay-offs are required to launch such coordination. Some coordination may, for example, correspond with objectives already developed in ministries, and some coordinated action may lead to a better situation for all participants than independent actions. In this view, the benefits of coordination must be set in relation to the transaction costs and other costs involved in coordination procedures.

It is not possible to determine the chances for coordination in an abstract way, because benefits and costs depend on the context of decisions. But this view makes it clear that all coordination needs the willingness of ministries to cooperate, and willingness depends on the 'profit' ministries can make by complying with coordination. Therefore, one cannot, under conditions of actors with equal powers, assume that coordination will be established if this means disadvantages for the interests involved. This immediately demonstrates the limits of 'interdepartmental bargaining' in the quest for 'policy coordination': only Pareto-optimal solutions are feasible. Purposive actor models do, however, allow for change as long as standard interests are not violated. 
Taking into consideration both 'sociological institutionalism' and 'purposive actor models', there seems to be only one way out and that is to make voluntary bargaining between ministries subject to the 'shadow of hierarchy' (Benz, 2006). If ministries can be obliged to find a cooperative solution that opens up the way for 'policy coordination', 'Kaldor' solutions may be acceptable, in which pay-offs create general welfare but where some players might lose in the distribution of values and resources (Scharpf, 1997). The obvious problem of the 'shadow of hierarchy' is that some consensus and coordination is already needed at another level, in this case the cabinet level, that is subject to its own restrictions. It is not a solution that can be found by actors on the ministerial level alone, as distributive interests are usually very strong, while it is possible at the cabinet level to establish a more 'rational' discussion of problem-solving (see below).

\section{Internal coordination}

Interdepartmental bargaining depends on the selfinterest of ministries, and coordination can occur only if benefits are higher than costs, there are no losers in the game, and the identity and organisational routines of each ministry are respected. Would it not then be better to overcome the distributive struggle that may undermine coordination efforts by simply dissolving corporate actors and/or creating new ones? Would it not be the easiest way to build one organisation, one 'superministry' responsible for the four policy sectors of the knowledge space? A large number of countries have embarked on this road without demonstrating convincing evidence so far that such a reorganisation is the best course of action (Arnold and Boekholt, 2003: 58).

Superministries seem, at a first glance, to be the obvious solution for 'policy coordination'. The four knowledge policy sectors can be united under one roof, and this means bringing them together under one leadership, one minister, who in principle has the authority to develop encompassing strategies and to oblige the divisions in ministries to comply with such plans. Costs and benefits are internalised within one organisation, which should lead to a reduction of negative externalities and hence more efficiency. Moreover, such a superministry would develop a 'standard interest' in pursuing cohesion of the knowledge space and link the different policy sectors if such a strategy were fixed from the outset in its 'constitution'. Transaction costs usually involved in bringing different ministries together could be reduced considerably. It is this 'idealised' picture of a superministry that has seduced many governments to use the organisational form of a superministry.

There are, however, a number of arguments that oppose such an idealised vision. These arguments can be briefly summarised as follows:
- The creation of one superministry may not overcome the need for internal coordination, as older administrative units may persist as subunits within the ministry, which would mean the maintenance of different cultures and worldviews.

- Hierarchical guidance is a function of the size and the span of control of the ministry (Hammond, 1990; Peters, 2001: 152; Arnold and Boekholt, 2003: 37). If the ministry is very large and heterogeneous in its composition, it may be difficult to apply commands, as information deficits will occur. The more complex an organisation gets, the more difficult it becomes to use hierarchical powers (OECD, 1987; Peters, 1998: 297). In addition, if the subject matter of the organisation is very diverse and technically demanding, and if it is difficult to apply standardised procedures and routines, hierarchy may not be applicable. This, however, is the case in all four knowledge policy sectors (Arnold and Boekholt, 2003: 37).

- Even if the responsible minister were able to develop encompassing plans and instruct the organisational units within the ministry about what and how to implement, the danger would still exist of 'creeping resistance' by organisational units opposed to the new views and plans and reluctant to adapt.

One argument, however, supports the creation of a new superministry. Peters has a very sceptical view of the value of organisational rearrangements and their effectiveness in the machinery of government (Peters, 1998: 17). According to him, it is not the choice of a specific organisational form that matters. More important is its symbolic value. The very fact that a superministry is created is important, because it indicates the willingness of the government to think differently about innovation policy and that it is prepared to give the knowledge space a high priority. New ministries can certainly also give a new élan to a policy sector or to the idea of coordination; new visions can be integrated into the 'constitution' of the ministry that determines the rationale of action, because of the leadership of a new minister, who still has to earn his or her merits, and because new institutions are generally more flexible and more innovative before they start to develop routines. This may provide the impetus for a new philosophy of innovation policy.

In other words, one should be cautious about embracing the institutional solution of a superministry without giving up hope. The study of Denmark, in this special issue of Science and Public Policy, that introduced a superministry in 2002 will reveal whether the scepticism is justified.

\section{Coordination at the agency level}

Intermediary agencies have a different significance for the four knowledge space sectors we are considering. They play a minor role in education, but a 
The very fact that a superministry is created is important, because it indicates the willingness of the government to think differently about innovation policy and to give the knowledge space a high priority

prominent role in both research and technological development. The establishment of such agencies in these policy sectors has a long tradition (Braun, 1997). While ministries for research and technology - or organisational subunits in ministries - have therefore often mediated access only to the policy field, it is different in the case of the education minister, for both higher and professional education. The vertical complexity of the policy sectors is therefore different.

The question of 'homology' or congruent structures plays a similar role on the agency level as on the sectoral level. In many countries the logic of the linear model of innovation has also been applied at the agency level with separate agencies for basic research on the one hand and technological research on the other. These agencies are usually attached to the ministry responsible for the sector in question.

According to the OECD there seems to be a trend towards delegating more tasks to such agencies in the hope that coordination would be easier at this level and more effective because of the proximity to the operating level in the sector. There are reasons to be doubtful about these assumptions:

- Intermediary agencies, which means in most cases funding agencies, very often have a legal status that puts them at some distance from political influence. They are seldom part of the public bureaucracy but have a 'quasi-public' or private status. Hierarchical orders by the responsible minister are therefore excluded, with a few exceptions, but this does not mean that the minister would be without influence. It is above all the 'power of the purse' that gives the minister access during budget negotiations. This can simply be by offering earmarked money for certain purposes or by concluding contracts with agencies. It is not infrequent, moreover, to see in the UK, Scandinavia, and the Netherlands, for example, that the government has the right to dissolve and (re-) establish agencies. If such a potential threat exists, the influence of the government over structures and policies of agencies grows.

- Intermediary agencies are often more closely linked to their clientele at the operative level than ministries (Braun, 1993; Braun and Guston, 2003) because they are in constant contact with their clientele, and because the clientele comprise part of the organisational structure of such agencies (Braun, 1998). These strong connections contribute to strong vertical relationships and the development of similar worldviews with clients in the various sectors. In this way, both basic research and technologically oriented agencies are well anchored in their respective networks, which makes cooperation across sectors as difficult as on the ministerial level, if not more difficult. At the ministerial level, there is still the possibility of 'command', even if internal resistance occurs; at the agency level such a command is usually not possible. In addition, intermediary agencies are mono-organisations, i.e. they are focusing on one sector only, while ministries often entail more than one sector, which contributes to a fragmentation of powers and objectives as well as loyalties inside the organisation. Organisational identities will therefore be even stronger at the agency level than at the ministerial level with ensuing difficulties in overcoming 'sectoral thinking'. This explains why evidence so far of attempts to create 'umbrella organisations' with several research councils under one roof or by creating new agencies is not met with much optimism about the capacity for reform at the agency level (Arnold and Boekholt, 2003: 39).

\section{Leadership at the cabinet level}

In order to be successful, both interdepartmental bargaining and superministries depend, as shown above, on decisions at the cabinet level. 'Policy coordination' needs an encompassing policy view at the cabinet level as a necessary condition. But who decides and when about new policy strategies and a reorganisation of the machinery of government?

The literature on the machinery of government (Davis et al, 1999) confirms that reorganisations of ministries and agencies are decided on the level of the cabinet, which in the Anglo-Saxon system means that the prime minister is the decisive policy-maker in launching such reorganisations. As the OECD discussed some time ago (OECD, 1987), however, the hierarchical system at the level of the cabinet is only one possible structure of decision-making. In addition we find the collective system, where cabinet decisions are made by deliberation among ministers, and the autonomous system, in which individual ministers are practically free to decide on their own policies. Both types of system make it much more difficult to come to a consensus on innovation policy, because as similar problems of 'voluntary bargaining' exist as they do on the ministerial level, but this time with no 'shadow of hierarchy' as there is no higher level of decision-making.

Even if we deal with a more hierarchical cabinet system with a strong leader, can we be sure that this is the obvious solution? The leader can, of course, 
decide on major reorganisations of the machinery of government. She can create a superministry or integrate some policy sectors into another ministry. She can oblige ministers to talk to each other and develop a common strategy ("bargaining in the shadow of hierarchy'). The leader has the authority to introduce new procedures of cooperation, to use committees in order to create benchmarks to achieve, and to create monitoring and evaluation institutions that can control compliance to coordination. However, one should be aware that all these measures would change only the institutional structure and that their influence on 'administrative coordination', on the cooperation of ministries and agencies in the implementation process, could still remain weak. This is the typical hierarchy problem we mentioned before that has led Peters to the conviction that hierarchy as a governance mode seldom suffices but needs to be complemented by bargaining between actors: cabinet decisions remain exogenous to policies in sectors if the ministers have not been part of decision-making; even if the ministers have had a voice, this does not guarantee that administrators will indeed obey. Implicit resistance may counteract such reforms.

One needs to understand moreover what can motivate political leaders to launch such fundamental reorganisations of the machinery of government. In a comparative analysis of the reasons for reforms in the machinery of government, Pollitt (1984) reveals a variety of motives that may lead prime ministers to reform: 'cabinet comfort', 'marking a change in emphasis', or 'creating an impression of reform' are examples of frequent motives. Less often we find preoccupation with effective governance, the 'functionality of policies' that react to changes in the environment and which must be the motivation it needs in order to launch a reform in innovation policy. When do leaders decide to react to changes in the environment?

In order to answer this question it is useful to refer to the policy change model of Braun and Gilardi (2006): policy-makers are above all influenced in their decisions by vote- and office-seeking. This means that if a topic is promising in terms of electoral gains or may be advantageous for gaining or maintaining office, it will have a chance to appear on the agenda of the leader. But there is more: the change of a policy, the introduction of a new policy innovation model, for example, depends on a comparison of the effectiveness of the existing policy innovation model and the availability of an alternative causal model that has a reasonable chance to be implemented. Only if both conditions are fulfilled and the topic has 'electoral appeal' will we see actions by the prime minister. The presence of an alternative model depends on the system of 'strategic intelligence' (see below).

These thoughts indicate that no decision at the cabinet level can occur without having the 'political business cycle' in mind. An encompassing innovation policy may be on the minds of leaders if it has been mediated by the logic of the political business cycle, i.e. if it pays in terms of office and votes. Then leaders can react, if they have the power to do so. In the 'collective system' and in the 'autonomous system' the consent of a large number of actors is also needed.

\section{Strategic intelligence}

The discussion so far has highlighted the extent to which the creation of congruent structures at the political level depends on the 'logic of political power'. The role of 'ideas' or 'puzzling' (Heclo, 1974) can, however, have an important influence on the reorganisation of the machinery of government. The dimension of 'ideas' is discussed in the OECD report under the title 'strategic intelligence' and refers to advisory bodies, foresight, and evaluation procedures in government.

Ideas certainly do not matter if decisions about reorganisation depend purely on 'cabinet comfort' or, in other words, on the political arithmetic of coalition-making. Ideas are often degraded to symbolic use in public discourse. If, however, problemsolving is taken seriously, if indeed the motive of reorganisation is the 'functionality of policies', ideas and with them 'strategic intelligence' have a chance to enter the political arena.

Scientific analysis of problems can help to detect flaws in existing and applied policy models and, above all, offer alternatives. Without such scientific and evidence-based reasoning, it would become more difficult to overcome existing policy models and their institutional structures. Scientists can also have an important transfer function in taking up and explaining dynamics at the operative level to policy-makers.

The most important function in this respect is the rationalisation of political debates. If it becomes possible to introduce convincing scientific arguments into the political debate, this may reduce the influence of 'distributive arguments' that prevail in the political business cycle in favour of problemsolving arguments. In order to do so, a forum is needed that allows scientific arguments to be heard. Pure scientific advisory bodies have the disadvantage that they are often too detached from direct discussion with policy-makers. This reduces their effect on consensus building. A more promising option has been presented in Finland and in Japan, where scientists are included in a top-level advisory body in which policy-makers and stakeholders participate and that is chaired by the prime minister (see the case study on Finland in this issue of Science and Public Policy). The direct contact can be helpful for rationalising political discussion.

In several countries, above all in Scandinavia, we also find advisory bodies located at the ministerial level and conceived to advise a particular ministry (Peters, 2005). The existence of advisory bodies at this level can be helpful if administrators from other 
Not only is it important that the cabinet level become involved in launching 'policy coordination' in innovation policy, but convincing arguments and alternative models as well as the willingness of leaders to engage in reforms of the functionality of policies are also needed

ministries also take part in the discussions. Only then can one expect that the subject of cooperation will appear on the agenda. If this is not the case, even such advisory bodies will remain within the logic of the policy sector in question.

Not only is it important that the cabinet level become involved in launching 'policy coordination' in innovation policy, but convincing arguments and alternative models as well as the willingness of leaders to engage in reforms of the functionality of policies are also needed.

\section{Overview of this special issue of Science and Public Policy}

The case studies of Finland, Denmark, Germany, and Switzerland in this special issue start from this conceptual framework and the questions put forth above. They attempt, first, to assess the specific institutional constellations and their capacity for overcoming existing fragmentation of knowledge and innovation policy at the level of the political system. This is a question not only of organising innovation-relevant policy areas by restructuring the composition of ministries, though this is an essential component (the horizontal dimension of coordination), but also of achieving 'vertical coordination'. The machinery of government dealing with knowledge sectors has a complex matrix structure that needs to be taken into account when assessing coordination capacities of countries' innovation policies.

In sum, we want to know how problems, opportunities, and solutions differ depending on different ways of institutionalising knowledge and innovation policies at the political level. Is it better, at the horizontal level, to use a superministry to improve coordination between knowledge policy sectors, or should we trust several ministries and, instead, improve external coordination mechanisms? If so, in what ways? What levels of authority are decisive in setting up vertical and horizontal coordination? Which institutions can foster the cohesion of innovation policies in general? These are the kind of questions all case studies are asking.
We do not pretend to give final answers to these questions. Instead we focus on a number of exemplary cases that might illustrate the variety of institutional options chosen, the pitfalls involved, and the range of solutions adopted.

We have chosen four countries with diverse institutional characteristics but also with sufficient similarities to be able to hold a number of variables constant that we are not interested in (such as the degree of economic development, transition countries vs. long-established democratic countries, etc.). This is why we have chosen only European countries. In regard to the institutional differences among these four countries, we have first selected countries with the most difficult institutional constellation in terms of fragmentation, i.e. federal countries that at the same time have designed at least two ministries to deal with the knowledge space (Germany, Switzerland). On the other hand, we have the Scandinavian unitary countries. Denmark and Finland differ in terms of fragmentation at the level of ministries: Denmark has introduced a 'superministry' dealing with all aspects of the knowledge space, while Finland has been working for quite some time with two ministries and a highly influential Science and Technology Council.

Finland is, of course, also usually regarded as a country with 'best practices' in innovation policy, which draws particular attention to the conduciveness of its institutional set-up. Denmark can offer important insights not only into how a 'superministry' is able to overcome institutional fragmentation but also into the rationality of 'internal coordination' as the best device for an encompassing innovation policy. Germany has a changing history of placing various knowledge policy areas into one or two ministries. This should also give important information about the changing influence this has had on coordination capacities. In terms of innovative capacities, Switzerland is a very successful country, but it works with a seemingly very awkward institutional structure, i.e. two ministries, a federal constellation, and an impotent high-level advisory council.

In sum, this special issue of Science and Public Policy is intended to give insights into the capacity of policy-makers to design cohesive and coherent policy by way of coordinating their machinery of government in knowledge and innovation policy. This can serve as a basis for further research that should take into account the lessons drawn from these case studies and use them in the context of a larger comparison of OECD countries.

\section{Notes}

1. We will consider only tertiary education here, though one could of course include primary and secondary education.

2. Which usually means that higher education and science and research policies are in one ministry, and professional education and technology policy in another. In contrast to this 'vertical segmentation' we may find a 'horizontal segmentation' 
(a research and technology ministry and an education ministry comprising higher and professional education). Other 'combinations' are, of course, possible but less frequent than this all-vertical segmentation. Integration, i.e. all four policy sectors integrated into one ministry, is the third alternative, which, at least at first sight, seems to reflect the congruent structure that would be needed to correspond to the innovation dynamics. Denmark, France, Spain, Ireland, Poland, Portugal, and Italy would be examples. As we will demonstrate, 'integration' at the level of ministries is, however, not yet a guarantee of successful coordination, and other coordination mechanisms may form viable alternatives.

3. Metcalfe developed a similar Guttman-scale on the base of 'management capacities' that coordination requires. 'Establishing central priorities', his second-highest coordination level, corresponds to our policy integration, and 'government strategy' to the highest level of 'strategic coordination' (Metcalfe, 1994).

4. Arnold and Boekholt (2003) do not mention the supra- and the international levels. Most European countries are bound into the European Union, which becomes more and more a player in research and technology and also in education policy. International treaties and cross-border networks between countries also increasingly influence what is decided in a country, and they may have an impact on the governance structures of countries. One can, for example, imagine the creation of coordination divisions within ministries that take care of jointly financed programs at the level of the EU or that deal simply with the coordination of policies between the EU and the country in question. The main influence, however, will be at the level of strategy development and funding decisions. We do not expect a major impact on institutionalisation policies concerning the knowledge space in one country, though.

5. 'The problems of managing horizontally are compounded when the issue of coordination among levels of government is added, especially in federal regimes such as Canada ... The fundamental root of the coordination problem in federal systems is that most federal regimes have evolved in ways that permit all levels of government to be involved in almost all policy areas.' (Peters, 2005: 5-6)

6. A procedure that demands that ministries distribute law proposals to other ministries before they are treated in government and parliament and that other ministries can signal their approval or disapproval according to how this proposal affects their own working. The ministry in question is supposed to take negative remarks into account and modify its proposal accordingly.

\section{References}

Arnold, Erik and Patries Boekholt 2003 Research and Innovation Governance in Eight Countries: a Meta-Analysis of Work Funded by EZ (Netherlands) and RCN (Norway). Brighton: Technopolis.

Benz, Arthur 2006 Eigendynamik von Governance. In Eigendynamik von Governance in der Verwaltung, eds. J Bogumil, W Jann and F Nullmeier, pp. 29-49. Wiesbaden: Verlag für Sozialwissenschaften.

Boekholt, Patries, Erik Arnold, E Deiaco, S McKibbin, P Simmonds and J Stroyan in collaboration with J de la Mothe 2002 The Governance of Research and Innovation: an International Comparative Study. Final Synthesis Report. Amsterdam.

Boston, Jonathan 1992 The problems of policy coordination: the New Zealand experience. Governance: an International Journal of Policy and Administration, 5(1), 88-103.

Braun, Dietmar 1993 Who governs intermediary agencies? Principal-agent relations in research policy-making. Journal of Public Policy, 13(2), 135-162.

Braun, Dietmar 1997 Die politische Steuerung der Wissenschaft. Frankfurt: Campus.

Braun, Dietmar 1998 The role of funding agencies in the cognitive development of science. Research Policy, 27, 807-821.

Braun, Dietmar and Fabrizio Gilardi 2006 Taking 'Galton's Problem' seriously: towards a theory of policy diffusion. Journal of Theoretical Politics, 18(3), 298-322.

Braun, Dietmar and David Guston eds. 2003 Special issue on principal-agent theory and science policy. Science and Public Policy, 30(5).
Davis, Glyn, Patrick Weller, Emma Craswell and Susan Eggins 1999 What drives machinery of government change? Australia, Canada and the United Kingdom, 1950-1997. Public Administration, 77(1), 7-50.

Edler, Jakob, Stefan Kuhlmann and Ruud Smits 2003 New Governance for Innovation: the Need for Horizontal and Systemic Policy Co-ordination. Six Countries Programme - the Innovation Policy Network. Karlsruhe.

Edquist, Charles 1997a Systems of innovation approaches: - their emergence and characteristics. In Systems of Innovation Approaches: Their Emergence and Characteristics, ed. C Edquist, pp. 1-35. London/Washington: Pinter.

Edquist, Charles ed. 1997b Systems of Innovation: Technologies, Institutions and Organizations. London/Washington: Pinter.

Edquist, Charles 1999 Innovation Policy: a Systemic Approach. Working Paper ISSN 1101-1289. University of Linköping: TEMA.

Etzkowitz, Henry and Loet Leydesdorff 2000 The dynamics of innovation: from National Systems and 'Mode 2' to a Triple Helix of university-industry-government relations. Research Policy, 29, 109-123.

Guston, David and Kenneth Keniston eds. 1994 The Fragile Contract: University Science and the Federal Government. Cambridge, Mass.: MIT Press.

Hammond, Thomas H 1990 In defence of Luther Gullick's notes on the theory of organization. Public Administration, 68, Summer, 143-173.

Heclo, Hugh 1974 Modern Social Politics in Britain and Sweden: from Relief to Income. New Haven: Yale University Press.

Jordan, Andrew and Adriaan Schout 2006 The Coordination of the European Union. Oxford: Oxford University Press.

Kuhlmann, Stefan and Jakob Edler 2003 Changing governance in European research and technology. In Changing Governance in European Research and Technology, eds. J Edler, S Kuhlmann and M Behrens, pp. 3-32. Cheltenham: Edward Elgar.

Kuhlmann, Stefan and Ruud Smits 2004 The rise of systemic instruments in innovation policy. International Journal of Foresight and Innovation Policy, 1(1/2), 4-32.

Lawrence, Paul R and J W Lorsch 1969 Organization and Environment. Homewood, IL: Richard D Irwin.

Leydesdorff, Loet 2000 The triple helix: an evolutionary model of innovations. Research Policy, 29, 243-255.

Lundvall, Bengt-Ake 1992 National Systems of Innovation. London/New York: Pinter.

March, James and Johan P Olsen 1984 The new institutionalism: organizational factors in political life. American Political Science Review, 78(3), September, 734-749.

March, James G and Johan P Olsen 1989 Rediscovering Institutions: the Organizational Basis of Politics. New York: Free Press.

Mayntz, Renate 1988 Funktionelle Teilsysteme. In Funktionelle Teilsysteme, eds. R Mayntz, B Rosewitz, U Schimank and R Stichweh, pp. 11-44. Frankfurt am Main: Campus.

Metcalfe, Les 1994 International policy co-ordination and public management reform. International Review of Administrative Sciences, 60, 271-290.

Meyer, John W and Richard W Scott eds. 1983 Organizational Environments: Ritual and Rationality. Beverly Hills/London: Sage.

Nelson, R 1993 National Innovation Systems: a Comparative Analysis. New York: Oxford University Press.

OECD, Organisation for Economic Development and Cooperation 1987 Strengthening the Cohesiveness of Policy-Making. Paris: OECD.

OECD 1999 Managing National Innovation Systems. Paris: OECD.

OECD 2005a Governance of Innovation Systems. Vol. 1: Synthesis Report. Paris: OECD.

OECD 2005b Governance of Innovation Systems. Vol. 2: Case Studies in Innovation Policy. Paris: OECD.

OECD 2005c Governance of Innovation Systems. Vol. 3: Case Studies in Cross-Sectoral Policy. Paris: OECD.

Painter, Michael 1981 Central agencies and the coordination principle. Australian Journal of Public Administration, 40, 265-280.

Peters, B Guy 1988 The machinery of government: concepts and issues. In The Machinery of Government: Concepts and Issues, eds. C Campbell and B G Peters, pp. 19-53. Pittsburgh: University of Pittsburgh Press.

Peters, B Guy 1992 Government reorganization: a theoretical analysis. International Political Science Review, 13(2), 199-217. 
Peters, B Guy 1998 Managing horizontal government: the politics of coordination. Public Administration, 76(2), 295-311.

Peters, B Guy 2001 The Politics of Bureaucracy. London: Routledge.

Peters, B Guy 2005 Concepts and theories of horizontal policy management. $X$ Congreso Internacional del CLAD sobre la Reforma del Estado y de la Administracion Publica. Santiago, Chile, 18-21 October 2005.

Peters, B Guy 2006 The Search for coordination and coherence. In Public Policy: Return to the Centre? Unpublished. Department of Political Science. University of Pittsburgh.

Pollitt, Christopher 1984 Manipulating the Machine: Changing the Pattern of Ministerial Departments 1960-83. London:
Allen \& Unwin.

Radin, Beryl A 2000 The instruments of intergovernmental management. In The Instruments of Intergovernmental Management, eds. B G Peters and J Pierre, pp. 607-618. London: Sage.

Scharpf, Fritz W 1973 Planung als politischer Prozeß. Frankfurt am Main: Suhrkamp.

Scharpf, Fritz W 1997 Games Real Actors Play: Actor-Centered Institutionalism in Policy Research. Boulder: Westview Press.

Scharpf, Fritz W 2000 Institutions in comparative policy research. Comparative Political Studies, 33(6-7), 762-790.

Stokes, Donald E 1997 Pasteur's Quadrant: Basic Science and Technological Innovation. Washington, DC: Brookings Institution. 